\title{
Seguridad humana: un desafío incuestionable
}

\author{
Human security: an unquestionable challenge
}

\section{Mirtha Graciela López Machín*}

\footnotetext{
* Docente de Derecho Notarial, integrante de la Cátedra de Metodología de la Investigación Jurídica y coordinadora académica de Monografías de Grado en la Facultad de Derecho de la Universidad CLAEH.

\gralop88@hotmail.com
}

\begin{abstract}
Resumen
Pensar la seguridad desde una dimensión integral y garantista de todas sus dimensiones resulta imprescindible para intervenir en cada uno de los aspectos que hacen posible que la persona se sienta a salvo de riesgos y amenazas ciertos o potenciales. Tratándose de un concepto evolutivo y rápidamente cambiante, el Estado, como responsable primario de su protección - por cuanto es un derecho inherente a la personalidad humana-, asume un rol de liderazgo imprescindible para construir una política de Estado sostenible, medible, participativa y flexible, capaz de recibir los ajustes y cambios que las variables intervinientes en hechos de violencia o vulneración determinan durante su aplicación, en forma oportuna y transdisciplinaria. Explorar y construir un concepto abarcador de seguridad humana amplía la visión de los operadores del derecho, los campos de intervención posibles y la participación de varios actores sociales en la cadena de causalidad de los hechos que generan inseguridad, y extiende la protección al hábitat, la cultura y aun a los fenómenos externos al Estado. Por esa razón, en el presente trabajo se reflexiona desde el derecho, desde la persona humana y desde la realidad social de nuestro país para propiciar un concepto omnicomprensivo que facilite un cambio más que necesario.
\end{abstract}

Palabras clave: seguridad humana, seguridad del Estado, Estado, derechos humanos. 


\begin{abstract}
Conceiving human security from a comprehensive, sage-guarding perspective, considering all its dimensions, is essential to intervene in each of the aspects that enables individuals to feel safe from actual or potential risks and threats. In the case of this evolving, rapidly changing concept, the State has the main responsibility for the fulfilment of people's protection rights, which are inherent to the human condition. The State assumes a leadership role, essential to build sustainable, measurable, participative and flexible State policies, receptive to the necessary adjustments and changes that the intervening variables in acts of violence or violation determine during their application, in a timely and transdisciplinary manner.

Exploring and building upon the comprehensive concept of human security broadens the vision of law for law operators, expands the possible fields of intervention, increases the participation of various social actors linked to the causality chain of facts that generate insecurity, and extends protection to the habitat, the culture and even to phenomena external to the State. For this reason, in the present time, we reflect on the law, humanity, and the social reality of our country in order to create an all-embracing concept to promote the urgent change required.
\end{abstract}

Keywords: human security, state security, state, human rights.

\title{
Introducción 1
}

La seguridad humana se plantea como uno de los grandes desafíos del mundo contemporáneo, caracterizado por la globalización y su capacidad de impacto en diversos ámbitos de la vida cotidiana de las personas y de las naciones.

La dinámica de las relaciones entre los países desdibuja cada vez más las fronteras territoriales de los Estados, lo que les permite adecuarse a los procesos de integración, a las exigencias comerciales generadas por la interdependencia económica, al intercambio cultural y migratorio.

Es en ese escenario interconectado que tienen las sociedades del siglo XXI que las fortalezas, oportunidades, amenazas y debilidades de unos y otros determinan mayor o menor estabilidad y seguridad para las personas individualmente consideradas y para los propios Estados como forma de organización de la vida comunitaria.

El presente trabajo es parte de una conferencia que junto al profesor emérito Dr. José Aníbal Cagnoni la autora brindó en oportunidad de las Jornadas Uruguayo-Santafesinas en honor de los profesores Sayagués Laso y Marienhof, que versó sobre la persona. Fue actualizado para la jornada académica organizada por la Facultad de Derecho de la Universidad CLAEH, realizada en Punta del Este, el 21 de junio de 2018, sobre seguridad y para esta publicación. 
En ese marco surgen algunos cuestionamientos insoslayables y actuales, que preocupan y ocupan a gobiernos y personas. ¿Es posible hablar de seguridad humana como un concepto universal que requiere el obrar de todos en un ámbito de articulación y convergencia? Si es así, ¿puede construirse un concepto abarcador que permita alcanzar un grado de identificación y consenso común sobre el cual construir en materia de seguridad y buenas relaciones humanas?

Sin duda, toda forma de convivencia está directamente asociada ab initio a las nociones de paz, dignidad humana y desarrollo humano sostenible, por lo que, a priori, necesita articulación, complementariedad y eficiencia en la elección de políticas adecuadas y oportunas que respeten particularidades de las personas asentadas en un territorio dado. En ese contexto, ¿cuál es el rol que debe cumplir el Estado constitucional de derecho?

\section{Antecedentes}

\section{El concepto genérico de seguridad y su impacto en la persona}

Etimológicamente, el vocablo seguridad proviene del latín securitis. En su sentido lato y llano es «calidad de seguro; confianza, tranquilidad calma, certeza, protección, firmeza, fianza, caución y garantía» (Diccionario enciclopédico ilustrado, 1966, s.n.f.; García Pelayo y Gross, 1969, p. 933).

Estar seguro es sentirse libre y exento de todo daño o riesgo, de necesidades, temores, acciones hostiles o, simplemente, de situaciones no previstas contrarias a la propia tranquilidad, vida o desarrollo.

El concepto razonablemente aceptado de seguridad es muy relativo y especialmente sensible a la situación coyuntural objetiva en cuyo marco se intente definir. Guarda una relación vinculante y estrecha respecto a un momento histórico-social y cultural dado; pero también tiene la necesaria cuota de subjetividad que proviene de la propia persona, de cómo esta se emplace en su relación e interacción con los factores objetivos que conforman su hábitat, que determinan sus condiciones de existencia y libertad.

Por esa razón, si la seguridad humana tiene su punto de partida en la persona, su contenido conceptual deberá tener presente que el concepto no puede ser una mera abstracción, sino que debe ser capaz de describir aspectos tangibles, perceptibles y que deberían ser indicadores aceptados de manera universal. 
El Prof. Dr. José Aníbal Cagnoni (1994), recordando al Prof. Dr. Justino Jiménez de Aréchaga, enseñaba que la seguridad implica adoptar un conjunto de medidas o precauciones que se toman para evitar sorpresas, librarse de peligros o defenderse de amenazas. Este sentido constituye el aspecto subjetivo del concepto, que no es otro que la mirada desde la persona humana. Conlleva el alcanzar la calidad de seguro, en la que la persona se percibe a sí misma como ausente de peligro y, en caso de que existan riesgos o amenazas, estos se encuentren debidamente controlados, para alejar el peligro de la vulneración de sus derechos. Quizás es lo que más modernamente se ha dado en llamar sensación térmica de seguridad o inseguridad.

En ese sentido, genérico, esencialmente psicológico, recoge el concepto nuestra carta magna en el artículo 7, desde la primera Constitución, de 1830. Si bien originalmente nació muy ligado a la idea de la seguridad individual, hoy se extiende a la seguridad humana, como necesario resultado del proceso evolutivo a que han dado lugar el derecho internacional de los derechos humanos y los desarrollos doctrinarios sobre el alcance del concepto paz.

En el artículo 31, en cambio, el concepto queda restringido a la seguridad individual, que se podrá ver limitada ante la adopción de medidas extraordinarias cuya finalidad es asegurar las garantías que deben darse cuando se determina democráticamente la existencia de un estado de excepción en el cual el Estado tiene que intervenir más fuertemente por razones de interés general y en cumplimiento de su deber de proteger, entre otros, el derecho a la seguridad inherente a la persona (Constitución de la República Oriental del Uruguay).

Nuevamente en los artículos 85 , numeral 3..$^{\circ}$ y 168 , numeral $1 .^{\circ}$, la Constitución retoma el concepto genérico, pero en este caso desde un punto de vista objetivo. Desde esa perspectiva la seguridad se expresa en hechos más o menos tangibles, demostrables, perceptibles por las personas. En el primer caso, por la existencia de leyes que establecen reglas claras y que se cumplen respecto a las conductas de las personas en ejercicio de sus derechos, que terminan cuando comienza el de los demás -o sea que permiten una convivencia en armonía-, las que dan cuenta de la independencia, la tranquilidad y el decoro de la República. En el segundo, a través de las nociones de orden, tranquilidad y libertad en lo interior y en lo exterior, que aseguran a la nación la preservación de su soberanía ante cualquier peligro.

Razonablemente, como podemos observar, es por esa causa que el concepto de seguridad es altamente relativo y especialmente sensible a la situación coyuntural objetiva que prime en determinado momento y lugar.

La concepción tradicional reduce la seguridad pública a dos órdenes de fenómenos, unos de orden social y otros políticos, sintetizados ambos en un concepto de orden público y de justicia penal, con un fuerte sentido represivo. 
Sin embargo, en las últimas décadas se ha ido produciendo un profundo cambio en la percepción del tema, que ha traído aparejadas profundas transformaciones, tanto en su gestión como en las estructuras y los procedimientos de las instituciones públicas que ejercen un monopolio en esta materia.

En efecto, de la mano del derecho internacional de los derechos humanos, por un lado, que denuncia los abusos y las desviaciones de poder de la gestión de la seguridad pública, y a través del desarrollo de la criminología, por otro, que introdujo nuevas visiones conceptuales y analítico-metodológicas sobre el fenómeno criminal, se ha avanzado para introducir un nuevo paradigma de la seguridad pública. Su principal pilar es la promoción de la participación del conjunto de la sociedad en la búsqueda de una acción eficaz, eficiente y legítima, coherente con las necesidades que plantea el desarrollo de la vida en comunidad.

Se podría sostener que actualmente transitamos hacia una teoría democrática de la seguridad pública, que se concibe necesariamente como una política de Estado, por cuanto no puede ni debe estar limitada a la visión del gobierno de turno ni es exclusiva de las instituciones públicas, sino que requiere la participación activa de las personas, que son quienes deben darle contenido y acción.

El fundamento jurídico de esta nueva teoría se encuentra en nuestro ordenamiento jurídico, en las bases mismas del Estado constitucional de derecho e, implícitamente, en la respuesta penal del Estado. Esta ya no puede pensarse solo como la imposición de una pena aflictiva, sino que debe apostar a la capacidad de reparación y rehabilitación de la personas, a la reconstrucción de las relaciones sociales alteradas por el conflicto de intereses, incorporando nuevas y diversas prácticas democráticas, alternativas de aquella, tales como la mediación, la conciliación, el principio de oportunidad, la libertad asistida, las penas alternativas a la privación de libertad, etcétera.

En ese sentido, es necesario utilizar una aproximación sistémica ${ }^{2}$ que facilite la identificación y la consideración de los problemas de la seguridad pública en sus diferentes ámbitos de expresión.

La actividad casi monopólica del Estado en materia de seguridad (que corresponde a la visión original y tradicional imperante hasta fines del siglo pasado) da paso al reconocimiento necesario de la existencia de otros actores, no solo públicos, sino privados y comunitarios, llamados a involucrarse en el diseño, la ejecución y la evaluación de la política de seguridad pública, sin que ello exima al Estado y a los agentes públicos de la tarea de control y de su responsabilidad por los resultados, no solo los obtenidos, sino también los no alcanzados.

2 El enfoque sistémico es una perspectiva teórica que nos permite comprender y explicar los comportamientos de las personas, no a partir de sus características individuales, sino en función de las relaciones que esas personas establecen con sus contextos más próximos. 
Este proceso de concepción de la noción de seguridad pública como bien común habilita también formas de autogestión del derecho a la seguridad personal y colectiva desde la organización social en los ámbitos nacional, regional o local, y conduce a un concepto integrador de la seguridad humana como dimensión abarcadora y envolvente de las demás.

Mediante la visión sistémica, la seguridad se transforma en una variable trascendente para la autosustentación del desarrollo social sin que nadie pueda atribuirse su propiedad exclusiva o excluyente. Es notorio un cambio sustancial del enfoque otrora represivo hacia modelos de prevención y promoción de derechos que requieren una amplia convocatoria y participación social sostenida, los cuales presentan la dificultad vinculada a su mayor alcance y profundidad, que hace que los resultados sean visibles a mediano y largo plazo. De allí también la necesidad de la evaluación permanente, correctora y oportuna para introducir cambios de rumbo cuando la realidad así lo determina.

A pesar de la existencia de estos nuevos paradigmas impulsados desde las Naciones Unidas en la década de los noventa, aún se sigue asociando el concepto de seguridad con lo policial, cuando en realidad la riqueza del concepto va mucho más allá e involucra cada vez más a otras instituciones y saberes multidisciplinarios e imprescindibles para su consideración y efectivización. Esa limitación supone un error porque se requiere algo más que la actividad policial. Si bien esta institución es una parte importante porque representa y actúa el vínculo relacional que existe entre el componente coactivo de la soberanía o ius edicendi (derecho de obrar) y la coerción para hacer efectivo el imperium del Estado, que se traduce en un poder de autoridad, la seguridad demanda una construcción colectiva a la que no pueden ser ajenos la familia, la educación, la salud, las ciencias jurídicas, la economía, la sociología, la antropología, la política, el deporte, la cultura y los valores axiológicos que comparten una sociedad dada y la sociedad internacional. No en vano nuestro país, cuando aprobó la Ley de Seguridad Ciudadana por unanimidad de todos los partidos con representación parlamentaria, consideró a la seguridad como un bien común.

Pensar la seguridad solo desde lo policial ha servido para limitar la posibilidad de alcanzar resultados mejores para el desarrollo de la vida humana en adecuada armonía con el hábitat, dejando sin participación preponderante a actores llamados a ejercer un rol fundamental en la construcción de soluciones acordes a las necesidades que plantea en cada momento y en cada territorio. Los países que han comprendido esta realidad, que han elaborado hojas de ruta comunes basadas en compromisos fuertes de los respectivos sectores integrados, son los que han logrado mayor satisfacción de las personas en cuanto a la visión de la seguridad, considerándola como derecho y como valor.

Una de las formas posibles de construcción de un trabajo en común en materia de seguridad es compartir saberes, apropiarse de lenguajes y prácticas propios de los 
diferentes actores sociales que deben aportar a la generación de conocimiento multi y transdisciplinario, para combatir la marginación cultural que hace que en un mismo pueblo o nación haya personas o grupos que no participen de los valores comunes que conciernen a la seguridad.

Sin duda, la seguridad guarda una relación vinculante, también, con la cuota de subjetividad que proviene de la propia persona, de cómo esta se emplace en su relación e interacción con los factores objetivos que conforman su hábitat y determinan sus condiciones de existencia y libertad. Si tiene las oportunidades adecuadas para desarrollarse conforme a sus potencialidades pero no las aprovecha, será su propia responsabilidad no alcanzar ese estado psicológico de sentirse seguro. Mientras con su conducta no afecte a otros, el problema queda circunscripto a su persona, pero si vulnera a otros, el Estado debe exigirle la adecuación de su conducta, llamarla a responsabilidad en los ámbitos que puedan corresponder y proporcionarle la ayuda para corregir su comportamiento a fin de evitar que se reitere.

Por ello, la noción de seguridad, en sentido general, pertenece al mundo psicológico de la persona. Constituye, respecto de cada ser en particular, un estado o situación subjetiva que tiene la particularidad de adquirir existencia real: se siente, se vive, se concreta en hechos. Así, se ha sostenido que la seguridad es el estado psicológico de la persona humana, producido por causas determinantes externas, que le permiten prever el futuro y adoptar una posición frente a él. Para ello el Estado debe garantizar en forma adecuada, pero también oportuna, que la persona, sus bienes y sus derechos no sean vulnerados, y que si lo fueran será sujeto de protección y eventual reparación.

A modo de resumen:

1. La seguridad implica una concepción integral muy amplia, que abarca los más diversos e increíbles aspectos de la vida humana, y por ello debe ser analizada, en primera instancia, de manera general, para posibilitar luego un análisis más profundo de los factores criminógenos, identificarlos y determinar la existencia de los criminorresistentes y de los criminovalentes para diseñar las acciones concretas de intervención estimulando a los primeros y minimizando a los segundos.

2. En ese sentido, las autoridades deben procurar alcanzar el equilibrio y la protección que permitan al Estado garantizar efectivamente la seguridad y la libertad, que no son valores antinómicos sino complementarios.

3. Ese estado de equilibrio y protección determinará siempre una situación relativa y dinámica, en permanente y constante evolución en el país y en el mundo, por la interdependencia y la comunicación que hoy tienen los pueblos y su gente. 
4. Pensar en términos de seguridad humana es pensar en un concepto complejo, multidisciplinario y necesariamente evolutivo que no puede desconocer las particularidades culturales y territoriales.

5. Es, a su vez, un cometido esencial de cualquier Estado constitucional de derecho que tiene el deber de asegurarla, en tanto es un derecho inherente a la personalidad humana, pero también un bien común; esto es, patrimonio de todos los miembros de la sociedad.

6. La seguridad humana se proyecta a todos los ámbitos internos del quehacer del Estado y de la vida de los individuos. Requiere la solidaridad entre estos y la cooperación y articulación de todas las instituciones que deben asegurar el interés general y el bienestar colectivo para construir esa seguridad que es bien común de todos.

7. Necesita, además, una muy buena coordinación entre Estados porque existe una estrecha relación entre la seguridad externa y la interna, así como una complementación entre el ordenamiento interno y el internacional.

8. Si la seguridad humana tiene su punto de partida en la persona, su contenido conceptual deberá tener presente que el concepto no puede ser una mera abstracción, sino que debe ser capaz de describir aspectos tangibles, perceptibles, que puedan elevarse a valores universales.

\section{Seguridad humana - derechos humanos}

Sentimos que es necesario, además, vincular el concepto de seguridad humana con la noción de garantía y con los principios de indivisibilidad, interdependencia e integralidad de los derechos humanos, lo que supone reconocer a priori que todos son igualmente importantes.

Los derechos humanos no solo garantizan derechos subjetivos de la persona humana, sino también principios objetivos básicos de orden jurídico universal que influyen de manera decisiva sobre el ordenamiento jurídico en su conjunto, legitimando y limitando el poder estatal. Generan, como consecuencia, un marco de convivencia humana propicio para el desarrollo libre de la personalidad, en tanto esencia de la condición humana. Cumplen una función fundamental al crear y mantener las condiciones básicas para asegurar el desarrollo de la vida en libertad, en condiciones compatibles con la dignidad humana. Ello es así porque la libertad individual solo es posible en una comunidad libre y viceversa, por cuanto presupone que las personas son capaces de decidir por sí sobre los temas que las involucran y de colaborar responsablemente con la comunidad.

Pero la libertad requiere condiciones materiales previas que habiliten la participación. Si la persona humana no dispone de medios básicos que garanticen un mínimo 
vital, en condiciones de dignidad, pocas serán las esferas propias que puedan protegerse de injerencias exteriores ilegales o arbitrarias.

En tal sentido, es oportuno recordar al Dr. Gregorio Peces Barba (1999), quien ha sostenido que existen tres modalidades de aplicación de la libertad que fundamentan tres tipos de derechos: libertad protectora o de no interferencia, cuando pretende que la persona pueda actuar y decidir libremente su propio comportamiento; libertad promocional, cuando pretende satisfacer una serie de necesidades básicas que impiden o dificultan el ejercicio de la libertad protectora, y libertad de participación, cuando pretende favorecer la intervención en la formación de los criterios de decisión política, contribuir al proceso de formación normativa y al restablecimiento de fines, objetivos y valores de la actividad del Estado.

\section{Seguridad humana - dignidad humana (como concepción común de los derechos humanos)}

Para referir al concepto de dignidad humana nos remitiremos a la palabra de tres grandes docentes de la Cátedra de Derechos Humanos de la Universidad de la República, en la conferencia que dictaron en la sesión de clausura del ciclo 2002 de la Cátedra UNESCO, realizada el 10 de diciembre de ese año en el Paraninfo de la Universidad de la República. En sus expresiones queda perfectamente comprendido el alcance y la importancia del concepto.

El Prof. Dr. Héctor Gros Espiell (2003, p. 13) sostuvo:

Todos los derechos humanos invocan un derecho común derivado del respeto integral a la dignidad humana, asentado en los principios de individualidad y diversidad, que supone reconocer que cada ser es único, idéntico solo a sí mismo y diferente de los demás que componen su especie.

Los derechos humanos y la dignidad humana, si bien están íntimamente relacionados, son conceptos diferentes. Así, el Prof. Gros Espiell (2003, p. 13) señala:

La dignidad humana, fundamento y base de una concepción común de los derechos humanos, no es sinónimo de estos. Es un concepto entrañablemente unido a ellos y, en consecuencia, inseparable de su naturaleza, declaración, promoción, respeto y protección, pero no es lo mismo.

La dignidad humana implica el necesario reconocimiento de que todos los seres humanos, iguales entre sí, son titulares, ontológicamente hablando, de una igual dignidad y que esta se integra con todos los derechos humanos, los civiles, los políticos, los económicos, sociales y culturales. 
La negación o el desconocimiento de uno, de algunos o de todos estos derechos significa la negación y el desconocimiento de la dignidad humana en su ineludible e integral generalidad.

[...] es un atributo de las personas humanas, de todos los seres humanos, sin ningún tipo o forma de discriminación.

La dignidad humana [...] entraña no solo la garantía negativa de que la persona no va a ser objeto de ofensas o humillaciones, sino que supone también la afirmación positiva del pleno desarrollo de la personalidad de cada individuo.

Pero es, también, un atributo de los pueblos, que en cuanto personas jurídicas colectivas, sujetos de derecho internacional, son titulares de una dignidad propia, que es el fundamento de los derechos de los pueblos.

Por su parte, la Prof. Dra. Jacinta Balbela (2003, p. 13) subrayó:

Por encima de todos los obstáculos estructurales, de todos los actos violatorios de los derechos humanos, de todas las expresiones del derecho positivo de cada país o región, «del abismo entre el derecho y la realidad», «de la opresión y la injusticia», por sobre todas las adversidades, ambiciones, odios, corrupción, debemos tener fe en el imperio de la dignidad como guía esencial de la conducta humana.

Ella no se consagra por obra de los textos formales; ella se reconoce, es innata al hombre por su condición de ser humano, sin distinción de raza, sexo, edad, idioma, color de la piel, credos políticos o religiosos, o filosóficos, o situación económica. Ella da vida a la fe en el triunfo de los derechos fundamentales, al valor de las personas, a la solidaridad, a la igualdad de hombres, mujeres y niños, a tornar realidad los niveles decentes de la convivencia, al trabajo, a la salud, a la razón de ser de los pueblos soberanos.

En otro plano, el Prof. Dr. Aníbal Cagnoni (2003, pp. 65-68) expresó:

El Preámbulo de la Carta de los Derechos Fundamentales de la Unión Europea afirma que el patrimonio espiritual y moral de la Unión se funda sobre los valores indivisibles y universales de dignidad humana, de libertad, de igualdad y de solidaridad. Y, al desarrollar el valor de la dignidad como primero en la Declaración, luego de proclamarla inviolable y de establecer el deber de respetarla y protegerla en el artículo $1 .^{\circ}$, la concreta en los artículos siguientes, en la integridad física y mental, y en la prohibición de las torturas, de las penas y tratamientos inhumanos y degradantes, de la esclavitud, de la servidumbre, de los trabajos forzados y de la trata de seres humanos. 
Sin duda, con ser esa una excelente concreción de la dignidad, se nos ocurre pensar que la dignidad responde a un concepto de extensión mayor en sus alcances respecto a la persona humana, pero sobre todo tiene naturaleza de valor esencial. La dignidad es consideración, respetabilidad, estimación, de cada uno por sí y con respecto a todos los demás; es lo que merece la persona humana por su humanidad; es lo adecuado a esta esencialidad que hace singular en el Universo a esta especie de seres vitales que somos los humanos.

Por ello, como afirma el artículo $1 .^{\circ}$ de la Declaración Universal, somos los humanos dignos de libertad y de igualdad y deudores mutuos de fraternidad. Solo que, y el detalle no es menor, la vida social organizada estatalmente ha oscilado entre regímenes enmarcados en el derecho positivo que, o han privilegiado la libertad en desmedro de la igualdad, produciendo desigualdades intolerables, es decir, indignas, o, en cambio, han pretendido imponer coactivamente la igualdad, ahogando la libertad y concluyendo en el mantenimiento o el ahondamiento de las desigualdades originarias.

Es que el derecho positivo, con ser necesario, no es suficiente: no es apto para asegurar la fraternidad, que no admite imposición en forma coactiva, pues el derecho positivo debe estar fundado en una fuerza moral que lo sostenga.

\section{El vínculo visible entre seguridad humana y paz en sentido positivo}

La noción de seguridad humana va adquiriendo, con este enfoque, una relación directa con la noción de calidad de vida adecuada, que dignifique a la persona, que la ponga a salvo de incertidumbres fomentando su desarrollo pleno, y ello no es posible si no hay paz en su entorno, lo que determina una relación vinculante entre ambas.

Asimismo, el concepto de paz social se relaciona directamente con las oportunidades que tienen las personas de lograr una vida mejor, libre de conflictos y de violencias. De este modo, la paz adquiere un significado positivo asociado a la identificación y resolución favorable de situaciones de vulneración o violencia, a la coparticipación de valores consensuados y respetados y no meramente negativos, esto es, como concepto opuesto a las nociones de guerra, beligerancia o conflicto.

Galtung, que otrora definió la paz en términos de ausencia de violencia y avanzó en los contenidos de esta última, da como pauta a tener en cuenta la diferencia entre realización y potencialidad:

La violencia está presente cuando los seres humanos se ven influidos de tal manera que sus realizaciones efectivas, somáticas y mentales, están por debajo de 
sus realizaciones potenciales. (Galtung, citado por Centro Internacional de Investigación e Información para la Paz, 2000, p. 21)

El mencionado autor distingue entre la paz positiva y la paz negativa. Esta se relaciona con la ausencia de violencia directa o personal, mientras que la primera se vincula a la ausencia de un tipo de violencia indirecta, estructural. Esos conceptos significaron un gran paso en las investigaciones sobre la paz y así ha sido reconocido, porque a partir de allí se comprende que «la paz no solo significa ausencia de guerra, sino también ausencia de otros tipos de violencia que limitan o impiden una relación de proximidad de lo realizado con lo potencial» (Galtung, citado por Centro Internacional de Investigación e Información para la Paz, 2000, p. 23); «cuando por motivos ajenos a nuestra voluntad no somos lo que podríamos ser o no tenemos lo que deberíamos tener» (Fisas, 1998, citado en Centro Internacional de Investigación e Información para la Paz, 2000). Así:

Si la ausencia de guerra podemos denominarla como paz negativa, la ausencia de violencia equivaldría a paz positiva, en el sentido de justicia social, armonía, satisfacción de las necesidades básicas (supervivencia, bienestar, identidad y libertad), autonomía, diálogo, solidaridad, integración y equidad. (Centro Internacional de Investigación e Información para la Paz, 2000, p. 23 in fine).

\section{Aproximándonos a algunos contenidos}

Podríamos decir que la seguridad humana es la situación en la que objetiva y subjetivamente la persona puede sentirse en armonía consigo misma, con los demás y con su hábitat, prever las consecuencias de su conducta, tomar precauciones para librarse de peligros o defenderse de amenazas en el marco de la convivencia humana, en la que deben primar la paz, la dignidad de la vida y la equidad de trato y oportunidades, y desarrollarse conforme a sus potencialidades. Determina un estado de paz en sentido afirmativo y no solo como ausencia de conflicto.

Frente a ella, el rol del Estado consiste en asegurar el hábitat de su pueblo para que permanezca libre de violencias y arbitrariedades, protegiendo la efectivización y el pleno goce y ejercicio de los derechos de sus nacionales y visitantes, porque es su razón de ser y porque es parte de compromisos universales que reconocen como valores indiscutibles todos los derechos inherentes a la personalidad humana. Su responsabilidad es la articulación en el ámbito interno y la cooperación en el ámbito internacional para la construcción de paz en sentido positivo y condiciones de vida dignas y sostenibles. 
La seguridad humana es un requerimiento irrenunciable inherente a la persona y a toda sociedad que se haya organizado en torno al Estado constitucional de derecho, que obliga a este a desenvolverse racionalmente y a brindar estabilidad y calidad de vida adecuada a todas las personas que habitan en su territorio sobre la base del irrestricto respeto a la libertad y la dignidad humanas. Es la nota esencial y distintiva de la civilización moderna universal, que sostenida por el Estado constitucional de derecho marca conductas en su realidad de interacción permitida o impedida por la conducta ajena en el ámbito coexistencial de todas las vidas humanas. Sin seguridad no es posible sostener el derecho a la vida, inseparable de las nociones esenciales que le son inherentes, como la integridad física, psíquica y social, así como el respeto irrestricto al significado que debe atribuirse a la dignidad, nota que distingue a la persona del resto de los seres vivos.

Del mismo modo, es esencial al derecho a la libertad personal, base del progreso personal, social y universal. Sin seguridad la libertad pierde la posibilidad de expresarse de un modo óptimo. La inseguridad se constituye en una barrera que limita el desarrollo pleno de la libertad al constreñir a la persona ante la incertidumbre. Las carencias aludidas se traducen en la pérdida real de calidad de vida individual y colectiva.

No bastan la seguridad jurídica y la confianza legítima sostenida por la coercibilidad de las normas jurídicas; también es necesario retomar y construir valores universales y propios de cada pueblo y obligarse a trabajar en común determinando deberes (por qué y para qué), indicadores y procedimientos de medición de resultados en forma periódica que permitan introducir las modificaciones que imponga la realidad sobre la que se actúa y las responsabilidades concomitantes.

Tampoco es suficiente acumular información y diagnósticos, sino que se requiere una acción oportuna y adecuada en tiempo y espacio. La respuesta debe ser el resultado de una intervención cierta, posible, continua, oportuna, transdisciplinaria, tangible para las personas; integral e integradora de todos los órganos que pueden construir seguridad humana a la medida que necesita una población asentada en una porción del territorio determinada, lo cual supone respetar sus particularidades para convencer, que no es otra cosa que vencer con el otro.

Sin duda, constituye un desafío para todo gobierno que debe realizar un ejercicio permanente de descubrimiento de todas las formas de violencia social, sea esta apreciable o encubierta, reconocerla o identificarla según corresponda, actuar conforme a la información procesada con todos los medios a su disposición, evaluar, reconsiderar y volver a la acción una y otra vez.

La seguridad humana debe constituirse en el reflejo de un orden universal de valores consensuados que obligue a todos por igual, prohibiendo, mandando o permitiendo hacer respecto de cada uno para con los demás y de los demás para con uno. Es un modo posible de ser de la vida humana, en lo individual y en lo colectivo, que se 
desarrolla en ese orden preestablecido y garantizado por el derecho, pero también, de cómo la persona se emplace en la relación e interacción con los factores que conforman su hábitat y sus condiciones de existencia.

Es necesario construir consensos y determinar objetivos precisos de actuación interinstitucional, claramente definidos, aceptados y cumplibles a corto, mediano y largo plazo; establecer los indicadores comunes y diferenciales y los procedimientos de evaluación para cada una de las instituciones participantes en las respuestas para la acción; suscribir un compromiso para la acción con clara delimitación de las obligaciones y responsabilidades de cada institución participante, acompañado de la hoja de ruta que indique de quién se recibe, para qué y a quién se deriva, por qué y para qué.

El rol del Estado es liderar, impulsar y controlar la articulación de todos los actores en el ámbito interno y mantener una buena cooperación en el ámbito internacional para alcanzar el máximo nivel de seguridad posible, como derecho y como valor. La seguridad debe asegurar el derecho de libertad, y este ser su marco de referencia. No hay verdadera libertad sin seguridad, ni seguridad sin libertad.

Su intervención debe considerar que la violencia es un hecho social, por lo que reconoce la cadena de causalidad que conduce al desarrollo de conductas inapropiadas para la vida en comunidad, por lo que se debe actuar tempranamente sobre las precondiciones sociales adversas que constituyen factores criminógenos contrarios a la dignidad humana y la efectivización de derechos, promoviendo los factores criminorresistentes y desestimulando los criminovalentes en cada porción de su territorio, en prevención primaria, secundaria y terciaria.

Tal como lo expresó nuestro prócer, José Artigas, en las Instrucciones del Año XIII, concretamente en la cuarta:

Como el objeto y fin del gobierno deber ser conservar la igualdad, libertad y seguridad de los ciudadanos y de los pueblos, cada provincia formará su gobierno bajo esas bases, a más del gobierno supremo de la nación. (Cayota, 2013, p. 30)

Como vemos, ya en ese momento la seguridad era concebida claramente como un fin y se la relacionaba directamente con los deberes propios de la actividad de gobierno.

\section{Algunas reflexiones en el marco de la cultura de la Universidad CLAEH}

No podemos dejar de considerar el concepto en el marco de la obra del padre Lebret y su Economía Humana, al que la Universidad CLAEH afilia por vocación y convicción. Tomaremos algunas ideas que el Prof. Mag. Julián Suquilvide suele recordar a 
nuestros educandos, las cuales son parte de un trabajo con el que se inició el Curso de Metodología de la Investigación Jurídica, en 2018. Fueron tomadas de la transcripción mimeografiada de un curso dictado por Lebret en la Facultad de Arquitectura de Montevideo en 1947 y de «Visión global de la Economía Humana», trabajo publicado en el número 89 de Économie et Humanisme, correspondiente a una exposición de L.-J. Lebret en una conferencia internacional de Economía y Humanismo celebrada en San Pablo en agosto de 1954, cuya actualidad nos exime de mayores comentarios.

Decía el padre Lebret (1954, s.n.f.) hablando sobre seguridad:

El hombre y sobre todo la familia tienen necesidad de seguridad. Esta necesidad comprende primeramente la posesión cierta y suficiente de bienes esenciales, como alimento, vestido, habitación.

Y agregamos sus aportes en materia de economía, que tienen directa relación con la seguridad humana:

Es en el seno de las unidades territoriales donde se satisfacen o no el conjunto de necesidades de una colectividad, en contraposición con lo que ocurre en las ramas de la actividad profesional, en las que cada uno solo satisface un área de necesidades. [...]

No basta registrar el nivel de vida individual o familiar, sino que hay que estudiar también los niveles de vida colectivos. No hay que proceder tomando como guía las medidas globales de nación, sino partir de las realidades regionales y de las capas sociales. No basta mirar lo «potencial» sino también lo «posible». No basta acumular datos, es necesario captar las estructuras. No es suficiente percibir una situación instantánea, hay que descifrar tendencias. (Lebret, 1954, pp. 28, 30)

Ha llegado el momento de pasar de la política intuitiva o aproximativa a la política que se apoya, no sobre la impresión o sobre la presión de las ambiciones, sino sobre la realidad debidamente analizada, y no solamente en función de algunos elementos cualitativos, sino en función de todas las necesidades de las masas humanas. (Lebret, 1947, p. 5)

\section{Conclusiones}

Derechos humanos y Estado constitucional de derecho mantienen entre sí una dependencia recíproca y se alcanzan en plenitud cuando se advierte que el último expresa verdaderamente en la ley la voluntad general, pues todos participan en su elaboración en igualdad de condiciones, de formación e información, y los derechos 
fundamentales no solo disfrutan de una garantía jurídico-formal sino también de un efectivo goce y ejercicio que se traduce en experiencias de vida reconocibles para todos y cada uno de los individuos.

Además de esos derechos fundamentales inherentes a la personalidad humana, es necesario tener presente que los derechos universales emergentes de la evolución histórica están sufriendo las amenazas y los peligros que se ciernen sobre nuestro planeta. Tal es el caso de la afectación del hábitat humano, del medioambiente, la explotación irracional de los recursos naturales en esencia finitos y la inadecuada de aquellos bienes que constituyen el patrimonio histórico y cultural de la humanidad, etcétera. De alguna manera, son expresiones que hacen visibles otras formas de violencia, con consecuencias colectivas sobre la paz social universal actual y futura.

Es deseable recordar que los derechos mencionados son, a la vez, valores, ideales superiores, trascendentes y universales. En cuanto tales, se encuentran indisolublemente ligados a la persona humana, único fundamento y justificación para la existencia de bienes trascendentes que deben constituirse en la razón de ser de la seguridad humana.

Por todo lo que acaba de expresarse, parecería que el siglo XXI plantea como un desafío e imperativo ético imprescindible e ineludible entablar un diálogo entre culturas que ayude a visibilizar las muchas formas de violencia visible y encubierta que afectan a la seguridad humana. Ese diálogo no es posible sin coordinación, articulación, convergencia e intervención informada y transdisciplinaria en torno a un mínimo de objetivos básicos y comunes que permitan dar seguridad garantizando la dignidad de la vida humana y la paz social, notas esenciales e inherentes a la naturaleza de la persona. Las cuatro actividades constituyen herramientas valiosas que pueden habilitar:

- la construcción de un universo armónico, que admita y respete la diversidad y la identidad culturales y facilite la convivencia humana sobre la base de la tolerancia y de la fraternidad;

- la elaboración de un concepto de paz que garantice la seguridad humana en libertad, equidad y desarrollo pleno de la persona;

- el goce efectivo de todos los derechos reconocidos como inherentes a la personalidad humana para todas las personas, cualquiera sea el lugar de la tierra donde habiten y, finalmente,

- la conformación de un hábitat favorable al desarrollo individual y colectivo de todos los seres humanos sin discriminación de especie alguna.

El concepto de seguridad humana presupone, a la vez, un derecho subjetivo para la persona y un deber para los Estados, tanto en el ámbito espacial que determina su territorio como en el hábitat universal, por lo que surge la imperiosa necesidad de la cooperación y complementación que garanticen la protección de su goce efectivo en el marco 
significativo que supone la existencia del Estado de derecho. Tiene las siguientes características:

- Su permanente evolución, dado que su definición debería ser el resultado de la enunciación actualizada de principios esenciales a la naturaleza humana, con especial énfasis en los conceptos de dignidad humana y libertad, calificables por la presencia de factores positivos que requieren reconocimiento y respeto universales, más que por la ausencia de factores de signo negativo.

- Su flexibilidad, inherente a su naturaleza, a su esencia, para poder admitir plenamente la diversidad cultural y adaptarse a circunstancias en permanente cambio y evolución.

- Su relación vinculante con el concepto de paz social y con la noción de garantía de los derechos humanos y los principios de indivisibilidad, interdependencia e integralidad que les son inherentes.

- Su cualidad para plantear en forma constante nuevas interrogantes; por ejemplo: ¿cuáles son los factores positivos a considerar en el contenido del concepto?; ¿cómo interactúan entre sí y respecto de aquellos de signo negativo?; ¿qué ponderación debe atribuírseles en la percepción de la seguridad individual y colectiva?, y tantas otras.

La seguridad humana se hace visible en un ambiente social que habilita un ejercicio estable y seguro de las opciones creadas por el desarrollo humano. De modo que no es suficiente un aumento de las oportunidades ofrecidas a las personas (ingresos, salud, educación, previsión, etcétera) si este no se da en un entorno que permita acceder a ellas y disfrutarlas como sujetos de un derecho que les pertenece.

Para que la seguridad humana sea realidad, se requiere dignidad, paz social, equidad, solidaridad, confianza. No es algo que las personas deben recibir pasivamente de las instituciones, sino una construcción social de todos.

Así como la seguridad jurídica tiende a sostener una regulación cierta, clara, estable, armónica, no contradictoria del orden del derecho; la seguridad individual tiende a proteger a la persona en sus condiciones de existencia y libertad; la seguridad social tiende a protegerla desde la cuna hasta la tumba frente a los desniveles que afectan su diario vivir, a causa de acontecimientos infelices, como la vejez y otros, o alegres, como las nuevas cargas de familia; la seguridad humana pretende ser una síntesis armónica extendida incluso a la protección de la naturaleza, a la cultura, a los fenómenos externos al Estado. Por ello hay que resaltar la importancia que adquieren en este sentido las normas de derecho público, particularmente las de derecho administrativo, y las de derecho público internacional, las cuales en mayor grado deben asegurar la realización de la seguridad humana y de la paz en el desarrollo de las rela- 
ciones e interrelaciones sociales, tanto en el ámbito nacional como en el internacional. Se asienta en el valor que alcanza el capital social logrado en una sociedad, definido como la acumulación de experiencias compartidas que han ido estableciendo redes, instituciones informales, lazos sociales, valoraciones comunes de lo que es positivo o negativo para el desarrollo, la convivencia y la identidad nacional.

\section{Bibliografía}

BAlbela, J. (2003). «El valor de la dignidad humana». En M. Blengio VALDÉs (coord.), La dignidad humana. Montevideo: Cátedra UNESCO de Derechos Humanos.

Cagnoni, J. A. (1994). Apuntes de clase de derecho público III. Montevideo: Facultad de Derecho, Universidad de la República.

CAGnoni, J. A. (2003). «La dignidad humana: Naturaleza y alcances». En M. Blengio VALDÉs (coord.), La dignidad humana. Montevideo: Cátedra UNESCO de Derechos Humanos.

CAyota, M. (2013). «Reflexiones e interrogantes en torno a las Instrucciones del año XIII». Transformaciones, 8 (52): 30.

CEntro Internacional de InVESTigación e Información PARA LA PAZ (2000). El estado de la paz y la evolución de las violencias: La situación de América Latina. Montevideo: Trilce.

Constitución de la República Oriental del Uruguay (1967). Asamblea General, Montevideo, Uruguay, 24 de agosto de 1966.

Diccionario enciclopédico ilustrado de la lengua española: Tomo IV (1966). Barcelona: Sopena.

García-Pelayo y Gross, R. (1969). Pequeño Larousse ilustrado. Buenos Aires: Larousse.

Gros EsPiElL, H. (2003). «La dignidad humana en los instrumentos internacionales sobre derechos humanos en dignidad humana». En M. BlEngIo VAldÉs (coord.), La dignidad humana. Montevideo: Cátedra UNESCO de Derechos Humanos.

LEBRET, J. L. (1947). Transcripción de un curso dictado en la Facultad de Arquitectura de Montevideo. (Manuscrito inédito).

LEBRET, J. L. (1954). «Visión global de la Economía Humana: Exposición realizada en una conferencia internacional sobre Economía y Humanismo». Economie et Humanisme, 89.

Peces Barba, G. (1999). Curso de derechos fundamentales: Teoría general. Madrid: Universidad Carlos III de Madrid. 